\title{
Study on Polymer Modified Cement-Based Coating with Healing Effect on Rusty Carbon Steel
}

\author{
Kunrong Wang, Zhiyong Liu, Zixiao Wang, and Weibin Yang \\ School of Civil Engineering, Yantai University, Yantai 264005, China \\ Correspondence should be addressed to Zhiyong Liu; lzy1698@163.com
}

Received 15 July 2014; Accepted 16 September 2014; Published 30 September 2014

Academic Editor: Flavio Deflorian

Copyright ( 2014 Kunrong Wang et al. This is an open access article distributed under the Creative Commons Attribution License, which permits unrestricted use, distribution, and reproduction in any medium, provided the original work is properly cited.

\begin{abstract}
The anticorrosion properties of polymer emulsion modified cement-based coating with healing effect on carbon steel were investigated. The change of linear polarization resistance $\left(R_{p}\right)$ and electrochemical impedance spectroscopy (EIS) have been used to measure the inhibitive and curative effect of electrodes painted with the coating in $3.5 \% \mathrm{NaCl}$ solution. The results indicated the high alkalinity of filler (cement) in coating can obviously improve the anticorrosion performance of coated steel electrodes. And the inhibitive ability of cement-based coating with fluoride acrylic emulsion is superior to that of the coating with epoxy emulsion. Moreover, by adding antirust pigments and rust converters in the fluoride acrylic emulsion modified cement-based coating, the inhibitive property was improved and the curative effect can be observed.
\end{abstract}

\section{Introduction}

Durability of concrete structures mainly depends on corrosion rate of steel bars in concrete. In search of ways to extend service life of steel bars in concrete structure is widely concerned by the civil engineering circles. Measures have been tried to inhibit corrosion of steel bars for the past decades. One popular way is application of a coating on the steel bars which can be effective in minimizing the rate of steel corrosion in concrete structures [1-3]. The most commonly used materials for protecting steel bars from corrosion were epoxy-resin-based coatings [4]. However, the brittleness of epoxy-resin made the coated steel bars more destructible in the process of construction and service. Once the coating is damaged at a local site, the localized anodic corrosion of the reinforcement bar will be accelerated. Furthermore, the higher cost of epoxy-resin caused the coated bars less and less application in reinforced concrete structures. The polymer modified cement-based coating was familiar to us and usually used on the surface of concrete for extending the service life of concrete structures. But fewer cases of the polymer modified cement-based coating are used for protecting the steel bars in concrete structures. Moreover, at present, many construction projects were delayed due to the excessive exploitation of real estate. Large numbers of exposed steel bars in the foundation of construction near the seaside would be eroded badly in a shorter time if no effective protective measures are to be adopted. In this paper the inhibitive and the curative effect of polymer emulsion modified cement-based coating for steel electrodes were assessed. The objective is to develop a polymer emulsion modified cement-based anticorrosion coating with healing effect on steel bar in chloride condition.

\section{Experimental Methods}

2.1. Coating Preparation. The polymer of film-forming and the filler have important effect on properties of the coating. For preparation of a high performance anticorrosion coating, in this study, two polymer emulsions and two kinds of filler were selected to test on the basis of considering the $\mathrm{PH}$, viscosity, toughness, strength, and corrosion resistance. And the coatings in this paper can be divided into four groups according to the selected materials. The first coating is epoxy emulsion modified heavy calcium carbonate coating (HYG). The second one is epoxy emulsion modified cementbased coating (HYC). The third is fluoride acrylic emulsion modified cement-based coating (FBC). In order to improve 


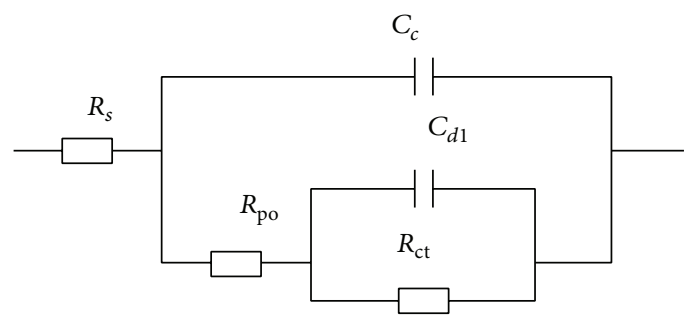

FIGURE 1: Equivalent electric circuit model.

the curative effect for rusty steel bar, the last one is prepared by adding antirust pigments and rust converters into the third one (FBC-RC).

2.2. Electrodes Preparation. The working electrodes were cut from low-carbon steel bars with the diameter of $12 \mathrm{~mm}$ and $15 \mathrm{~mm}$ in length. The chemical composition (wt \%) of carbon steel is C 0.19, Si 0.02, Mn 0.37, P 0.011, S 0.019, and balance $\mathrm{Fe}$. One end of the electrode was connected with wires and then the steel segment was placed in the PVC tube filled with epoxy-resin. The electrodes were polished by silicon carbide sandpapers in the sequence of grade 240, 320, 800, and 1000. Subsequently, they were cleaned in ethanol solution, rinsed with deionized water, and finally dried in dryer.

2.3. Electrochemical Measurements. The PARSTAT2273 and three-electrode arrangement were used to perform the electrochemical measurements. Saturated calomel electrode (SCE) and platinum electrode were used as the reference electrode and the counter electrode. Before painting coating, the working electrodes of three specimens for each group were immersed in $3.5 \% \mathrm{NaCl}$ solution for one hour and then the surface of electrodes was rusted. Moreover the linear polarization resistance $\left(R_{p}\right)$ and electrochemical impedance spectroscopy (EIS) were measured. Then the electrodes were removed from the solution and coated with the four coatings, respectively. $24 \mathrm{~h}$ later, the electrodes of surface painted coating were immersed in $3.5 \% \mathrm{NaCl}$ solution once again. The $R_{p}$ and EIS were measured after immersion in the solution $1 \mathrm{~h}, 3 \mathrm{~d}, 7 \mathrm{~d}, 14 \mathrm{~d}$, and $21 \mathrm{~d}$. The corrosion current $\left(I_{\text {corr }}\right)$ of electrodes is calculated by the formula: $I_{\text {corr }}=B / R_{p}[5]$. The $B$ value of $26 \mathrm{mV}$ is usually used for the active state, whereas value of $52 \mathrm{mV}$ is more appropriate for the passive steel $[6,7]$. EIS was also used to confirm the corrosion rate, conducting at $E_{\text {corr }}$ with the ac perturbation amplitude of $10 \mathrm{mV}$ in the frequency range from $100 \mathrm{kHz}$ to $1 \mathrm{MHz}$ [8]. An equivalent circuit model (EC) with two time constants was used in the EIS data fitting, as shown in Figure 1. In $\mathrm{EC}, R_{s}$ is the resistance of electrolyte. $R_{\mathrm{po}}$ is the resistance of the steel/coating interface. $C_{c}$ is the capacitance of coatings. $R_{\mathrm{ct}}$ and $C_{\mathrm{dl}}$ are charge transfer resistance and double electric layer capacitance, respectively. Charge transfer resistance is defined as the limiting zero frequency value of the real part of the complex impedance. It has been reported that charge transfer resistance is more intimately related to the corrosion rate than the polarization resistance [9].

\section{Results and Discussion}

3.1. Effect of Filler Alkalinity on Anticorrosion Properties. Figure 2(a) lists the linear polarization resistance $\left(R_{p}\right)$ values and the corrosion current densities $\left(I_{\text {corr }}\right)$ of the electrodes coated with $\mathrm{HYG}$ and $\mathrm{HYC}$ coatings in $3.5 \% \mathrm{NaCl}$ solution at different immersion time. Compared with the HYG coatings, the $R_{p}$ values of steel electrodes coated with HYC coatings are improved after painting coatings. And the corrosion current densities $\left(I_{\text {corr }}\right)$ of steel electrodes coated with HYG coating are larger than $10 \mu \mathrm{A} \cdot \mathrm{cm}^{-2}$ after immersing in the solution $7 \mathrm{~d}$, indicating serious corrosion occurs of the steel electrodes. However the corrosion current densities of steel electrodes coated with HYC coating are below $1 \mu \mathrm{A} \cdot \mathrm{cm}^{-2}$ after immersing in the solution $7 \mathrm{~d}$, indicating the electrodes coated with HYC coating are in a state of moderate corrosion. Figure 2(b) depicts the Nyquist plots of electrodes painted with HYG and HYC coatings after immersing in $3.5 \% \mathrm{NaCl}$ solution at different time. The low frequency arcs are caused by electrical double-layer capacitor and the polarization resistance of steel electrodes. The semidiameters of low frequency arcs of steel electrodes coated with HYC are larger than those of steel electrodes coated with HYG. And the phases of electrodes painted HYG and HYC coatings after immersing in the solution at different time are shown in Figure 2(c). The low frequency phases of HYG coatings decrease with time. However the low frequency phases of HYC coatings increase with time. This indicated the high alkalinity of cements obviously improved the anticorrosion performance of coatings.

3.2. Effect of Emulsions on Anticorrosion Properties. Figure 3(a) lists the linear polarization resistance $\left(R_{p}\right)$ values and the corrosion current densities $\left(I_{\text {corr }}\right)$ of the steel electrodes coated with HYC and FBC coatings in the solution at different immersion time. Compared with the HYC coatings, the $R_{p}$ values of steel electrodes coated with FBC coatings are improved in the chloride solution within $21 \mathrm{~d}$. The corrosion current densities $\left(I_{\text {corr }}\right)$ of steel electrodes coated with HYC coating are larger than $1 \mu \mathrm{A} \cdot \mathrm{cm}^{-2}$ after $14 \mathrm{~d}$, indicating serious corrosion occurs to the steel electrodes. However the corrosion current densities of steel electrodes coated with FBC coating are below $1 \mu \mathrm{A} \cdot \mathrm{cm}^{-2}$ in the chloride solution within $21 \mathrm{~d}$. The steel electrodes coated with FBC coating are in a state of moderate corrosion. Figure 3(b) depicts the Nyquist plots of steel electrodes coated with HYC and FBC coatings 


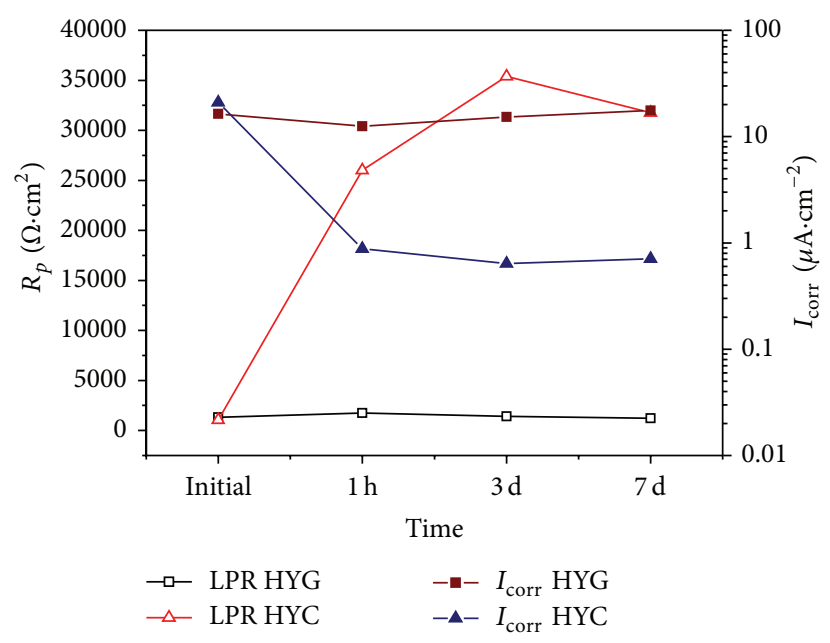

(a) $R_{p}$ and $I_{\text {corr }}$ plots

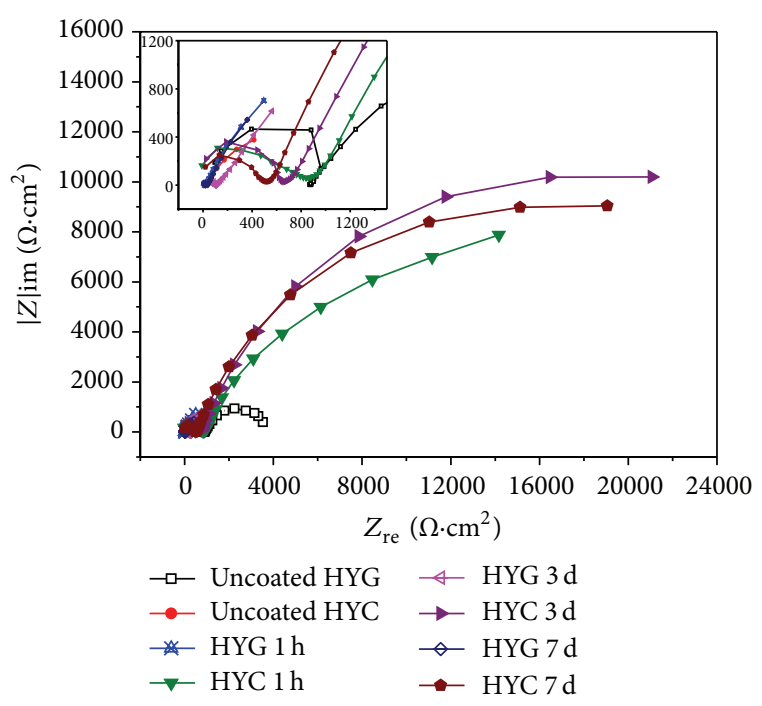

(b) Nyquist plots

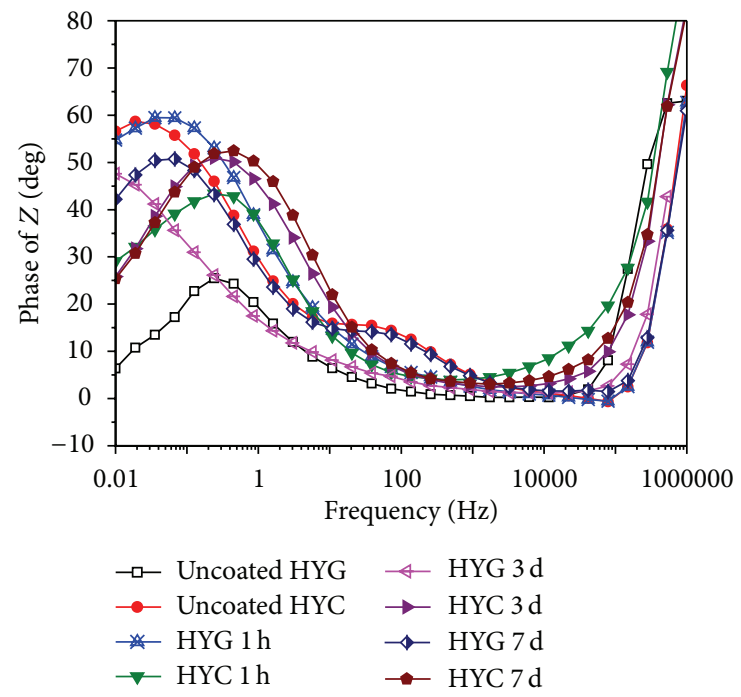

(c) Bode plots

FIGURE 2: LPR and EIS plots of electrodes coated with HYG and HYC in chloride solution.

immersed in the solution at different time. The semidiameters of capacitive arcs of the steel electrodes coated with FBC coatings are greater than HYC coatings. And the phases of electrodes painted $\mathrm{HYC}$ and FBC coatings after immersing in the solution at different time are shown in Figure 3(c). The low frequency phases of FBC coatings are larger than those of HYC coatings. The results are consistent with the $R_{p}$ tests.

3.3. Effect of Pigments and Rust Converters on Healing Performance. Figure 4(a) lists the linear polarization resistance $\left(R_{p}\right)$ values and the corrosion current densities $\left(I_{\text {corr }}\right)$ of the electrodes coated with FBC and FBC-RC coatings in the solution at different immersion time. Compared with the FBC coatings, the $R_{p}$ values of the electrodes coated with FBC-RC coating are improved distinctly in the solution after $7 \mathrm{~d}$. And the corrosion current densities $\left(I_{\text {corr }}\right)$ of the electrodes coated with $\mathrm{FBC}$ coating are around $1 \mu \mathrm{A} \cdot \mathrm{cm}^{-2}$, indicating serious corrosion occurred in the steel electrodes. However the corrosion current densities of the electrodes coated with FBC-RC coatings are below $0.5 \mu \mathrm{A} \cdot \mathrm{cm}^{-2}$ in the solution within $14 \mathrm{~d}$, indicating the steel electrodes were in a state of mild corrosion. Figure 4(b) depicts the Nyquist plots of specimens coated with FBC and FBC-RC coatings immersed in the solution at different time. Obviously the semidiameters of capacitive arcs of the electrodes coated with FBC-RC coatings are greater than FBC coatings. And the phases of electrodes painted FBC and FBC-RC coatings after immersing in the solution at different time are shown in Figure 4(c). The low frequency phases of FBC-RC coatings are larger than those of FBC coatings in the solution after $7 \mathrm{~d}$.

The results are in line with the $R_{p}$ tests. The charge transfer resistance was modeled with EC by EIS. The comparison of $R_{p}$ and $R_{\mathrm{ct}}$ is shown in Table 1. The variation trend of the $R_{\mathrm{ct}}$ values fitted by $\mathrm{EC}$ is consistent with the $R_{p}$ values. 
TABLE 1: Comparison of $R_{p}\left(\mathrm{k} \Omega \cdot \mathrm{cm}^{2}\right)$ and $R_{\mathrm{ct}}\left(\mathrm{k} \Omega \cdot \mathrm{cm}^{2}\right)$.

\begin{tabular}{|c|c|c|c|c|c|c|c|c|}
\hline \multirow{3}{*}{ Time } & \multicolumn{8}{|c|}{ Coating } \\
\hline & \multicolumn{2}{|c|}{ HYG } & \multicolumn{2}{|c|}{ HYC } & \multicolumn{2}{|c|}{ FBC } & \multicolumn{2}{|c|}{ FBC-RC } \\
\hline & $R_{p}$ & $R_{\mathrm{ct}}$ & $R_{p}$ & $R_{\mathrm{ct}}$ & $R_{p}$ & $R_{\mathrm{ct}}$ & $R_{p}$ & $R_{\mathrm{ct}}$ \\
\hline Initial & 1.3 & 0.9 & 1.1 & 0.93 & 8.8 & 9.1 & 1.0 & 1.9 \\
\hline $1 \mathrm{~h}$ & 1.7 & 1.2 & 26.0 & 13.1 & 95.6 & 45.7 & 42.2 & 31.0 \\
\hline $7 d$ & 1.2 & 0.9 & 31.8 & 17.8 & 26.4 & 17.7 & 73.7 & 49.1 \\
\hline $14 \mathrm{~d}$ & 0.8 & 0.6 & 20.8 & 11.2 & 21.1 & 13.0 & 50.0 & 34.5 \\
\hline $21 \mathrm{~d}$ & 0.7 & 0.5 & 13.1 & 8.3 & 26.4 & 13.7 & 63.9 & 35.1 \\
\hline
\end{tabular}

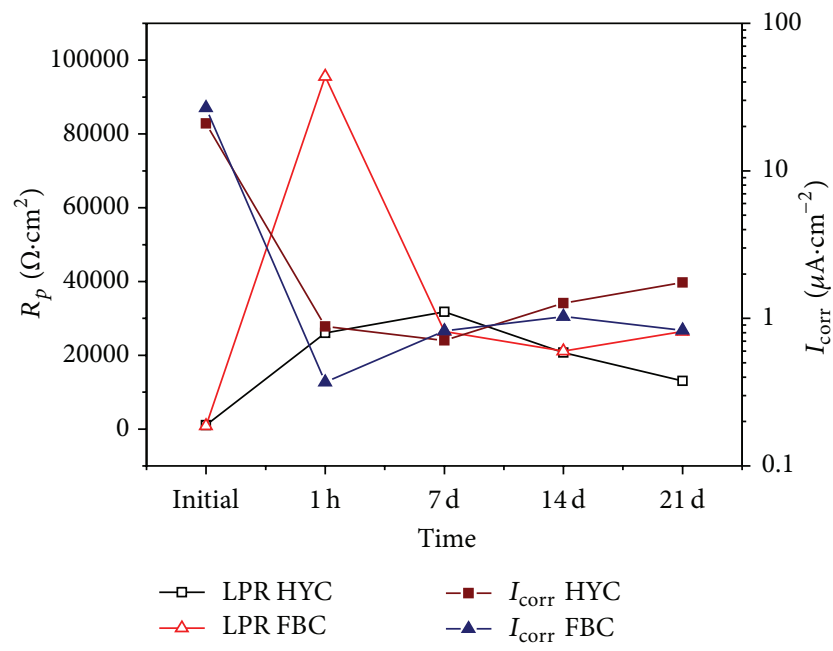

(a) $R_{p}$ and $I_{\text {corr }}$ plots

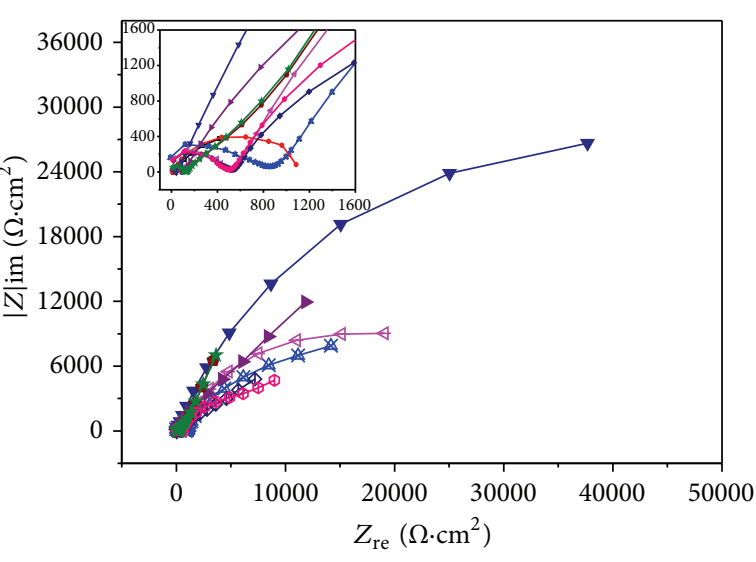

$\begin{array}{ll}\rightarrow-\text { Uncoated HYC } & \rightarrow \text { FBC } 7 \mathrm{~d} \\ \rightarrow \text { Uncoated FBC } & - \text { HYC } 14 \mathrm{~d} \\ \star \text { HYC } 1 \mathrm{~h} & \rightarrow \text { FBC } 14 \mathrm{~d} \\ \rightarrow \text { FBC } 1 \mathrm{~h} & \rightarrow \text { HYC } 21 \mathrm{~d} \\ \rightarrow \text { HYC } 7 \mathrm{~d} & \rightarrow \text { FBC } 21 \mathrm{~d}\end{array}$

(b) Nyquist plots

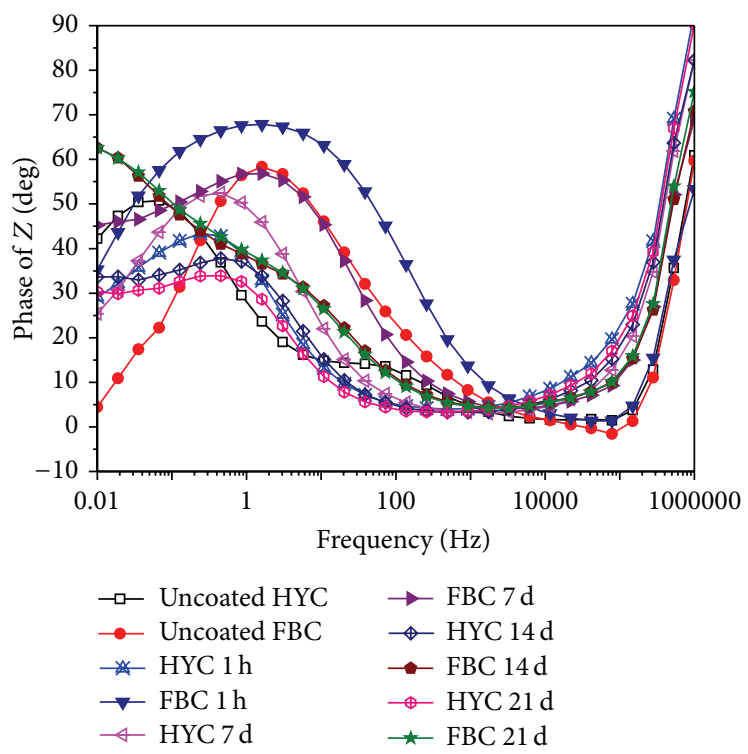

(c) Bode plots

FIGURE 3: LPR and EIS plots of electrodes coated with HYC and FBC in chloride solution. 


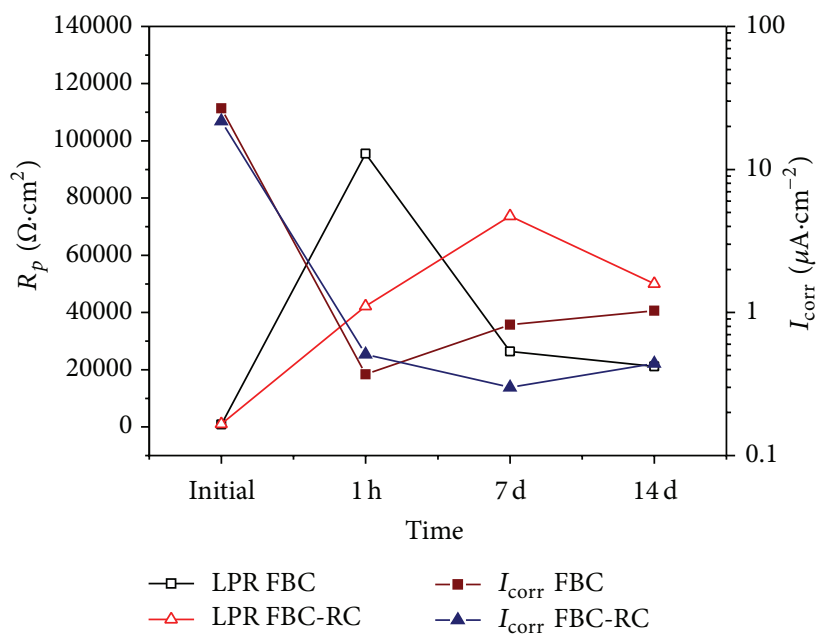

(a) $R_{p}$ and $I_{\text {corr }}$ plots

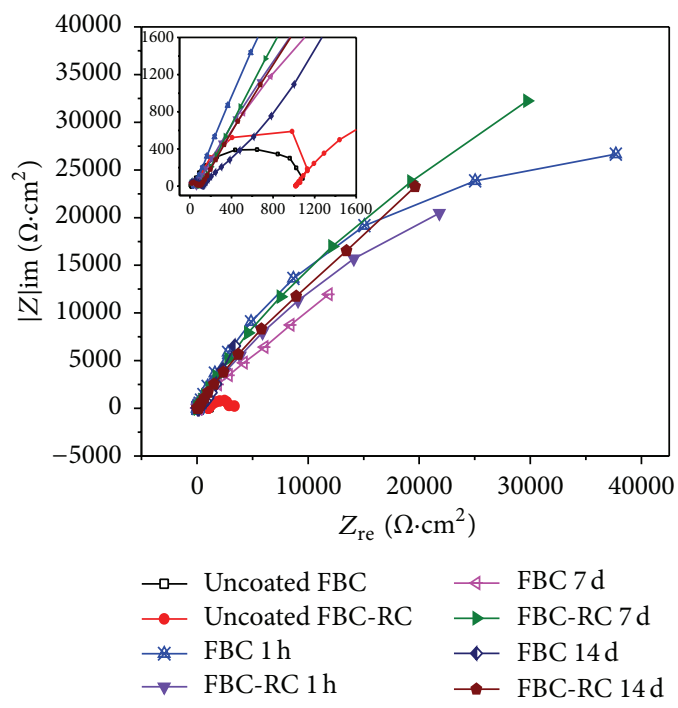

(b) Nyquist plots

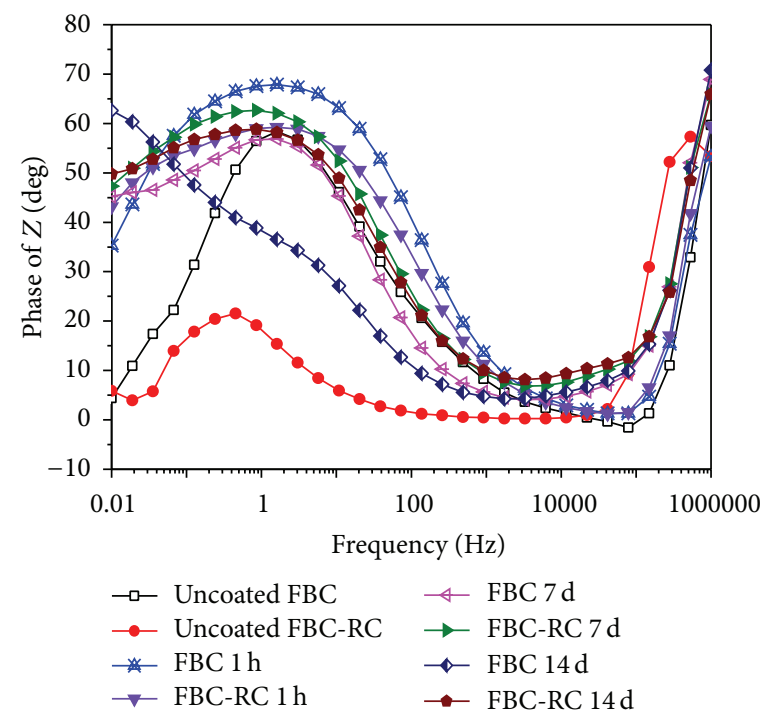

(c) Bode plots

FIGURE 4: LPR and EIS plots of electrodes coated with FBC and FBC-RC in chloride solution.

The $R_{\mathrm{ct}}$ of specimens coated with different coatings at the same time of soaking from initial to $21 \mathrm{~d}$ in the following order: FBC-RC > FBC $>$ HYC $>$ HYG. And the anticorrosion property of FBC-RC coating is the most excellent of all the coatings.

\subsection{Comparison of Four Kinds of Coating Anticorrosion} Performance. Figure 5 lists the corrosion current densities $\left(I_{\text {corr }}\right)$ of the electrodes coated with four kinds of coating in the solution at different immersion time. And the corrosion current densities of the electrodes coated with FBC-RC coating after $21 \mathrm{~d}$ are far lower than those of other three kinds of coating, indicating FBC-RC coating has an excellent anticorrosion performance. And the phases of electrodes painted with four kinds of coating after immersing in the solution at $1 \mathrm{~h}$ and $21 \mathrm{~d}$ are shown in Figure 6. The low frequency phases of FBC-RC coatings are larger than those of other three kinds in the solution after $21 \mathrm{~d}$, proving the $\mathrm{FBC}$ $\mathrm{RC}$ coating has a good anticorrosion effect.

\section{Mechanism Analyses for Curative Effect}

Firstly, due to the polymer emulsion composed of insulating macromolecule organic compound, the high resistance of polymer can hinder the ionic migration from the cathode or anode to the solution. So the polymer emulsion modified cement-based coating has good physical shielding effect on corrosive medium. And the resistance of fluoride acrylic emulsion is higher than that of epoxy emulsion. 


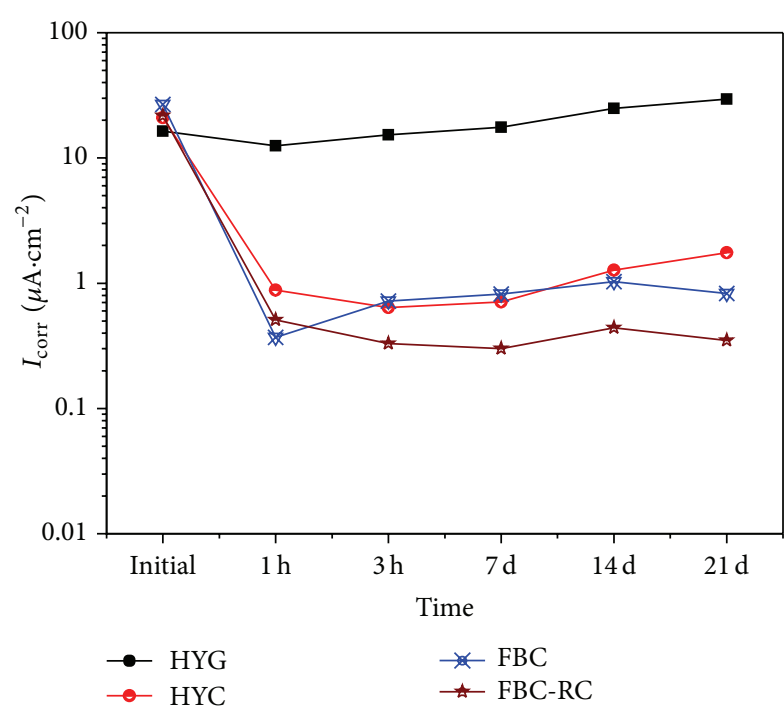

FIGURE 5: $I_{\text {corr }}$ plots of electrodes coated with four kinds of coating in chloride solution.

Secondly, the high alkalinity of cement can form $\gamma-\mathrm{Fe}_{2} \mathrm{O}_{3}$ and $\gamma$-FeOOH passivation membrane on the surface of steel to protect it from being corroded $[10,11]$ :

$$
\begin{gathered}
2 \mathrm{Fe}_{3} \mathrm{O}_{4}+2 \mathrm{OH}^{-} \longrightarrow 3 \gamma-\mathrm{Fe}_{2} \mathrm{O}_{3}+\mathrm{H}_{2} \mathrm{O}+2 \mathrm{e}^{-} \\
\mathrm{Fe}_{3} \mathrm{O}_{4}+\mathrm{OH}^{-}+\mathrm{H}_{2} \mathrm{O} \longrightarrow 3 \gamma-\mathrm{FeOOH}+\mathrm{e}^{-}
\end{gathered}
$$

Thirdly, at the anodic zinc phosphate reacts with ferric iron to generate complex. The anodic reaction is inhibited:

$$
\mathrm{Fe}^{3+}+3 \mathrm{Zn}^{2+}+3 \mathrm{PO}_{4}{ }^{3-} \longrightarrow \mathrm{Fe}\left[\mathrm{Zn}_{3}\left(\mathrm{PO}_{4}\right)_{3}\right]
$$

And the zinc ion reacts with hydroxide ion to generate sediment layer of zinc hydroxide at the cathode. The cathode reaction is inhibited [12]:

$$
\mathrm{Zn}^{2+}+2 \mathrm{OH}^{-} \longrightarrow \mathrm{Zn}(\mathrm{OH})_{2} \downarrow
$$

Furthermore, aluminum hydroxide can provide aluminum ion, the aluminum ion reacts with rust, and then the rust is dissolved. Moreover, zinc phosphate reacts with ferrous ion. The phosphate film is formed to inhibit the corrosion of steel.

\section{Conclusions}

The high alkalinity of filler (cement) in coating can obviously improve the anticorrosion performance of coated steel electrodes. The anticorrosion property of fluoride acrylic emulsion modified cement-based coating is superior to that of epoxy emulsion modified cement-based coating. Moreover, by adding antirust pigments and rust converters in the fluoride acrylic emulsion modified cement-based coating, the anticorrosion property was significantly improved and the healing performance can be observed. The excellent anticorrosion property may be closely related with the good

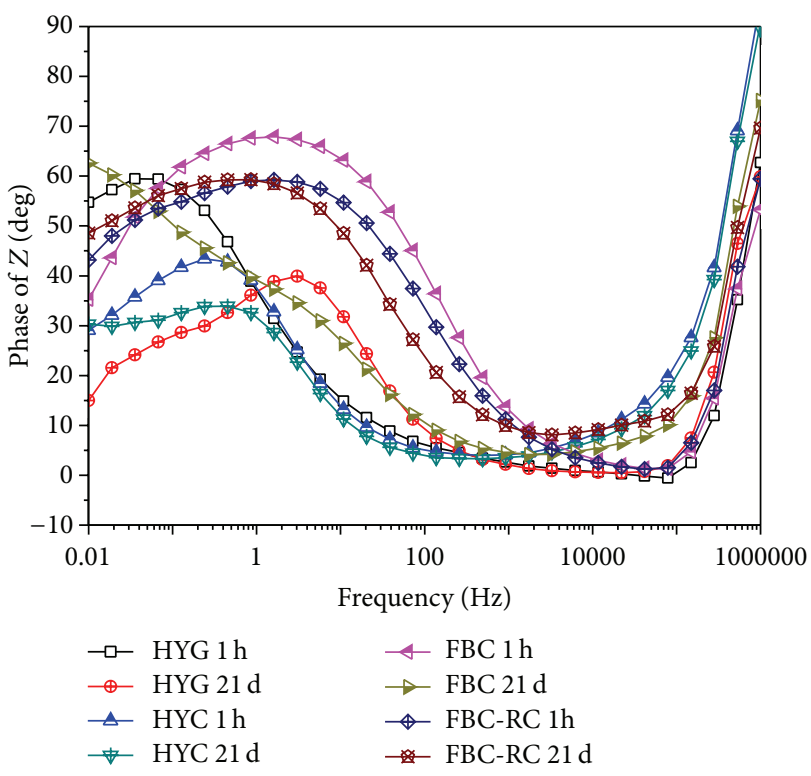

FIGURE 6: Bode plots of electrodes coated with four kinds of coating in chloride solution.

physical shielding of cement and polymer, and the curative effect of the coating is some link with the formation of passivation membrane, the appearance of phosphate film, and sediment layer on the surface of steel.

\section{Conflict of Interests}

The authors declare that they have no conflict of interests regarding to the publication of this paper.

\section{Acknowledgments}

Thanks are due to the finical support by the National Natural Science Foundation of China (no. 51278443) and the Shandong Natural Science Foundation (ZR2011EEM006).

\section{References}

[1] M. L. Zheludkevich, D. G. Shchukin, K. A. Yasakau, H. Möhwald, and M. G. S. Ferreira, "Anticorrosion coatings with self-healing effect based on nanocontainers impregnated with corrosion inhibitor," Chemistry of Materials, vol. 19, no. 3, pp. 402-411, 2007.

[2] M. M. Al-Zahrani, S. U. Al-Dulaijan, M. Ibrahim, H. Saricimen, and F. M. Sharif, "Effect of waterproofing coatings on steel reinforcement corrosion and physical properties of concrete," Cement and Concrete Composites, vol. 24, no. 1, pp. 127-137, 2002.

[3] H.-S. Lee, T. Noguchi, and F. Tomosawa, "Evaluation of the bond properties between concrete and reinforcement as a function of the degree of reinforcement corrosion," Cement and Concrete Research, vol. 32, no. 8, pp. 1313-1318, 2002.

[4] J.-Y. Wu, S.-G. Wu, X.-F. Xu, and N.-X. Xu, "Epoxy-coated rebar and its application," Corrosion and Protection, vol. 25, no. 3, pp. 105-108, 2004. 
[5] M. Stern and A. L. Geary, "Electrochemical polarisation: a theoretical analysis of the shape of polarisation curves," Electrochemical Society, vol. 104, no. 1, pp. 56-63, 1957.

[6] C. Andrade and J. A. González, "Quantitative measurements of corrosion rate of reinforcing steels embedded in concrete using polarization resistance measurements," Werkstoffe und Korrosion, vol. 29, no. 8, pp. 515-519, 1978.

[7] C. Andrade and C. Alonso, "Corrosion rate monitoring in the laboratory and on-site," Construction and Building Materials, vol. 10, no. 5, pp. 315-328, 1996.

[8] J.-J. Shi and W. Sun, "Electrochemical and analytical characterization of three corrosion inhibitors of steel in simulated concrete pore solutions," International Journal of Minerals, Metallurgy and Materials, vol. 19, no. 1, pp. 38-47, 2012.

[9] L. A. Al Juhaiman, A. A. Mustafa, and W. K. Mekhamer, "Polyvinyl pyrrolidone as a green corrosion inhibitor for carbon steel in alkaline solutions containing $\mathrm{NaCl}$," Anti-Corrosion Methods and Materials, vol. 60, no. 1, pp. 28-36, 2013.

[10] L. Freire, X. R. Nóvoa, M. F. Montemor, and M. J. Carmezim, "Study of passive films formed on mild steel in alkaline media by the application of anodic potentials," Materials Chemistry and Physics, vol. 114, no. 2-3, pp. 962-972, 2009.

[11] M. Sánchez, J. Gregori, C. Alonso, J. J. García-Jareño, H. Takenouti, and F. Vicente, "Electrochemical impedance spectroscopy for studying passive layers on steel rebars immersed in alkaline solutions simulating concrete pores," Electrochimica Acta, vol. 52, no. 27, pp. 7634-7641, 2007.

[12] T. S. Zhang, H. Zhang, and H. Gao, Corrosion Inhibitor, Chemical Industry Press, Beijing, China, 2008. 

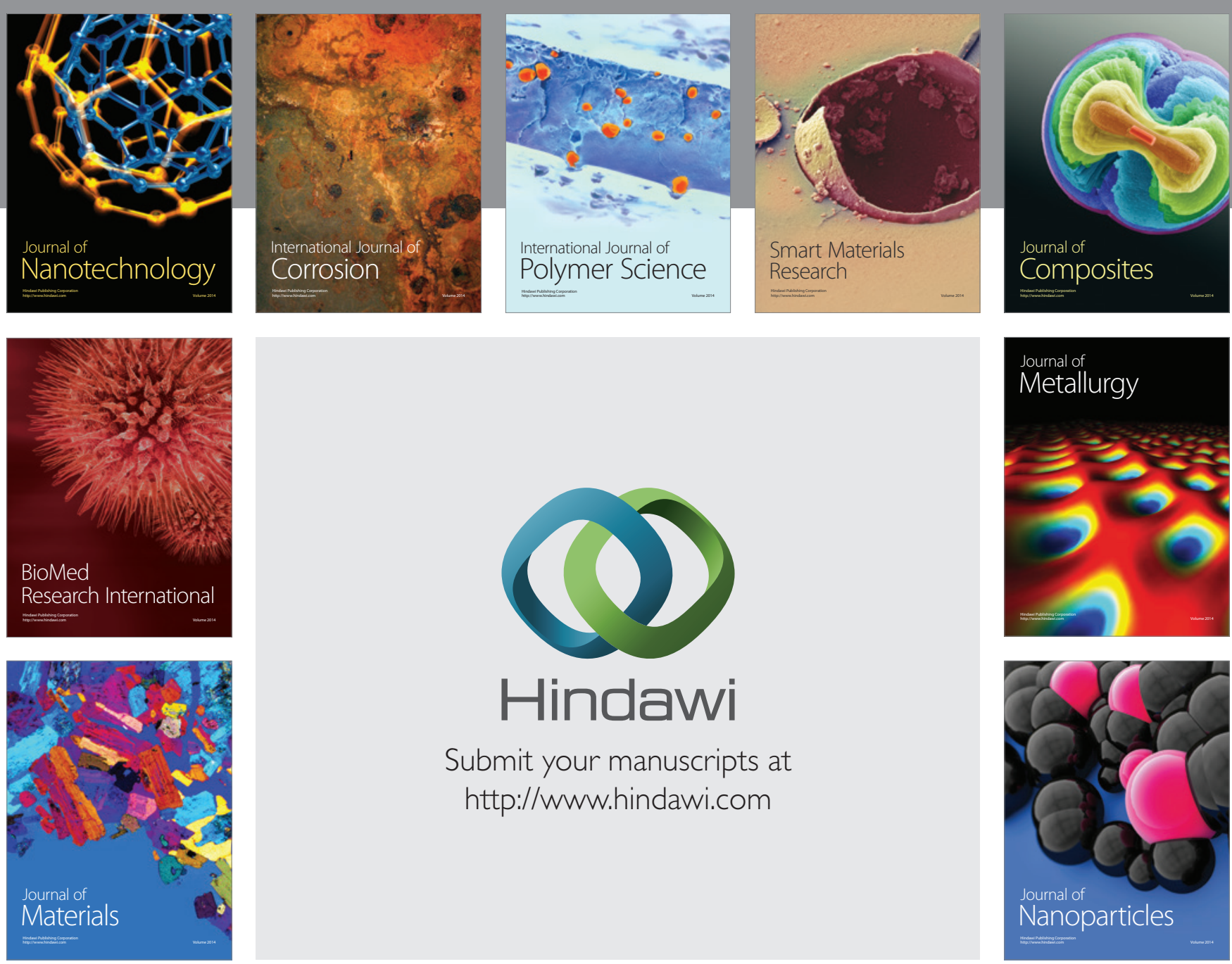

Submit your manuscripts at http://www.hindawi.com
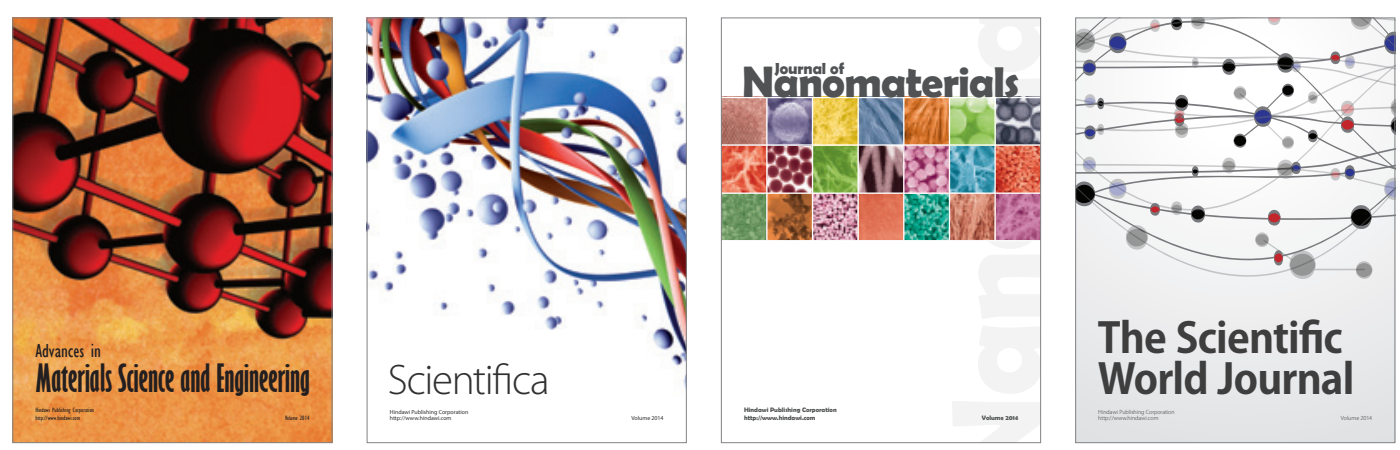

\section{The Scientific World Journal}
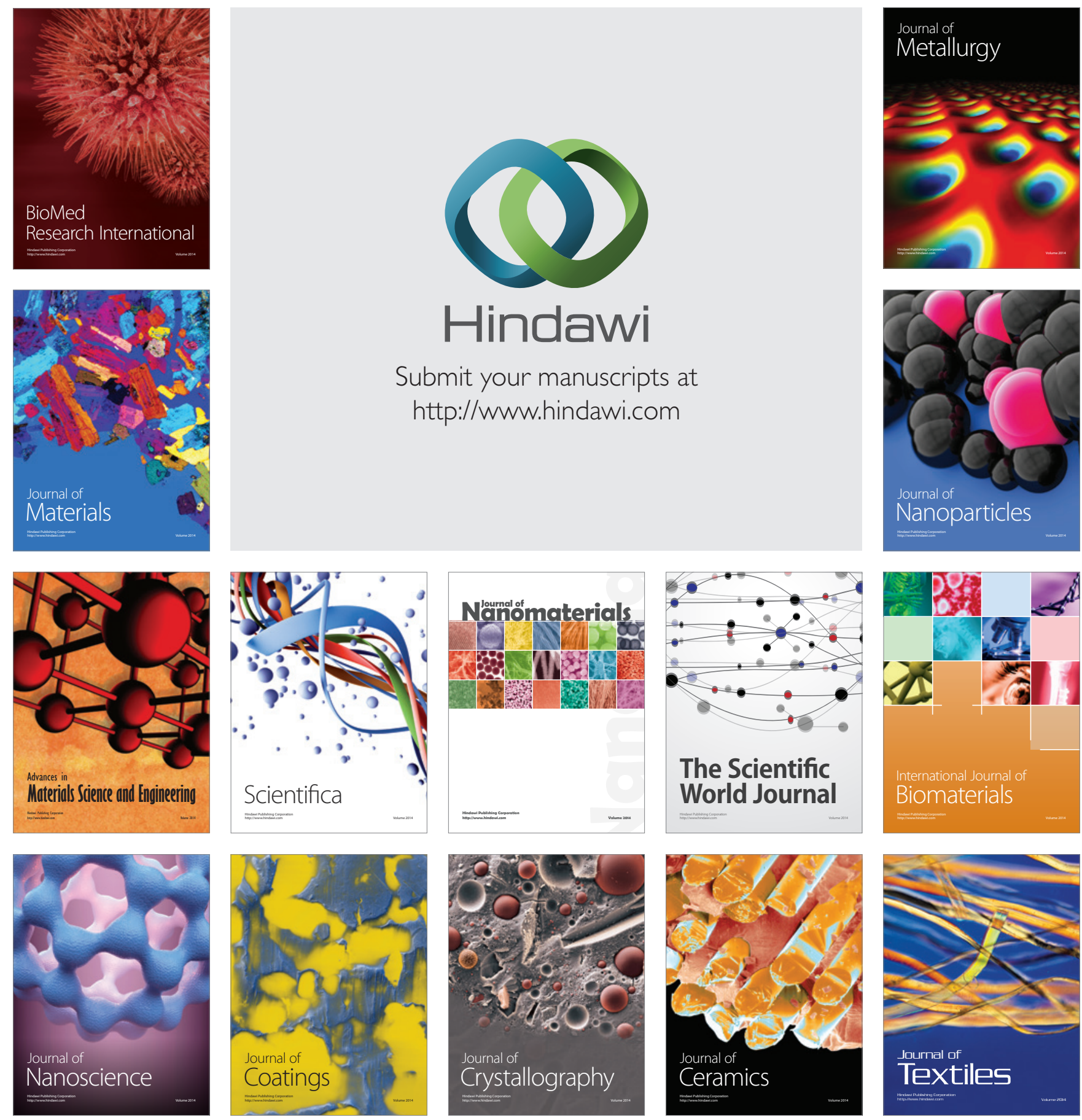